\title{
Timing is essential for rapid effects of corticosterone on synaptic potentiation in the mouse hippocampus
}

\author{
Olof Wiegert, ${ }^{1}$ Marian Joëls, and Harm Krugers
}

\author{
Swammerdam Institute for Life Sciences_Center for Neuroscience, University of Amsterdam, Kruislaan 320, 1098 SM \\ Amsterdam, The Netherlands
}

\begin{abstract}
Stress facilitates memory formation, but only when the stressor is closely linked to the learning context. These effects are, at least in part, mediated by corticosteroid hormones. Here we demonstrate that corticosterone rapidly facilitates synaptic potentiation in the mouse hippocampal CAl area when high levels of the hormone and high-frequency stimulation coincide in time, but not when corticosterone is given either before or after repetitive stimulation. This effect could not be blocked by antagonists of the mineralocorticoid receptor and glucocorticoid receptor (spironolactone and RU 38486, respectively). These data provide a biological substrate for the important behavioral observation that stress and corticosteroid hormones can facilitate learning and memory processes.
\end{abstract}

Corticosteroid hormones (corticosterone in most rodents, cortisol in humans) are released in high amounts from the adrenal gland after exposure to stress; hormone levels rise within 5-10 min, peak $\sim 30 \mathrm{~min}$, and normalize within 60-90 min after stress exposure (de Kloet et al. 2005). Corticosterone enters the brain and binds to intracellular receptors, which act as transcription factors; recently, rapid non-genomic effects have also been reported in brain, not only for corticosterone (Di et al. 2003; Kruk et al. 2004; Karst et al. 2005), but also for other steroid hormones (for review, see Losel et al. 2003).

Corticosteroid hormones are key factors in the effects of aversive and emotional situations on learning and memory processes, both in humans and animals (Lupien and McEwen 1997). Stress and elevated corticosteroid hormone levels hamper the retrieval of previously learned information as well as impair the acquisition and storage of additional information (Krugers et al. 1997; de Quervain et al. 1998; Roozendaal et al. 2003; Kuhlmann et al. 2005). Yet, stress and corticosterone are known to facilitate memory formation when they form an intrinsic part of the learning context or are given in close conjunction to a learning test (Sandi and Rose 1994; Roozendaal and McGaugh 1996; Oitzl et al. 2001). The neurobiological substrate for this behavioral observation, however, is not very clear. Thus, hippocampal synaptic potentiation-currently the best documented substrate for learning and memory formation involving the hippocampus (Bliss and Collingridge 1993)—was consistently found to be impaired instead of facilitated by earlier applied stress or high levels of corticosterone (Pavlides et al. 1996; Xu et al. 1997; Kim and Diamond 2002). It has been postulated that stress or corticosterone may prime synaptic circuits such that the threshold for synaptic potentiation induced $1-2 \mathrm{~h}$ later is enhanced (Kim and Yoon 1998). We hypothesized that synaptic potentiation will be facilitated when corticosterone and induction of potentiation coincide in time, as is likely to occur during stressful learning conditions, rather than being events that are separated in time.

Male C57/black6 mice ( $\sim 6 \mathrm{wk}$ of age) were obtained from Harlan $\mathrm{CPB}$. Upon arrival the animals were individually housed with food and water ad libitum available. The animals were kept at $20^{\circ} \mathrm{C}-22^{\circ} \mathrm{C}$, humidity was $55 \% \pm 15 \%$. Lights were on from 8 a.m. until 8 p.m. The experiments took place between $7 \mathrm{~d}$ and 14

\footnotetext{
'Corresponding author.

E-mail owiegert@science.uva.nl; fax 00-31-20-5257709

Article published online ahead of print. Article and publication date are at http://www.learnmem.org/cgi/doi/10.1101/lm.87706.
}

$\mathrm{d}$ after arrival, and were approved by the local committee on animal bioethics of the University of Amsterdam.

Animals were decapitated between 8 a.m. and 9 a.m. Directly after decapitation, trunk blood samples were collected and analyzed for plasma corticosterone levels with an $\mathrm{I}^{125}$-corticosterone radioimmunoassay for mice (MP Biomedicals). We presently analyzed samples from 20 randomly selected animals involved in our study. Next, the brain was removed from the skull and stored in chilled artificial cerebrospinal fluid (aCSF) equilibrated with $95 \% \mathrm{O}_{2}$ and $5 \% \mathrm{CO}_{2}$. The aCSF contained (in $\mathrm{mM}$ ): $\mathrm{NaCl}$ (120); $\mathrm{KCl}$ (3.5); $\mathrm{MgSO}_{4}$ (1.3); $\mathrm{NaH}_{2} \mathrm{PO}_{4}$ (1.25); $\mathrm{CaCl}_{2}$ (2.5); D-glucose (10); $\mathrm{NaHCO}_{3}$ (25.0). After separation of the two hemispheres the hippocampus was dissected, and transverse hippocampal slices $(\sim 400 \mu \mathrm{m}$ thick) were prepared with a manual tissue chopper. Subsequently, the slices were transferred to a storage bath and were allowed to equilibrate for $1 \mathrm{~h}$ at room temperature in oxygenated aCSF.

Slices were transferred into a slice chamber where they were kept submerged in aCSF at a temperature of $31.5^{\circ} \mathrm{C}$. The bath aCSF was refreshed with a rate of $2.5 \mathrm{~mL} / \mathrm{min}$ and equilibrated with $95 \% \mathrm{O}_{2}$ and $5 \% \mathrm{CO}_{2}$. Bipolar stimulation electrodes $(60-\mu \mathrm{m}$ stainless steel wires insulated except for the tip) were placed on the Schaffer collaterals, and glass recording pipettes (filled with buffer) were positioned in the CA1 stratum radiatum, to record field excitatory postsynaptic potentials (fEPSPs). At the start of the experiment, an input-output curve was established for the slope of the fEPSP, from which half-maximal stimulation intensity was determined. This intensity was used throughout the remainder of the recording session. After establishing the inputoutput curve, we monitored baseline synaptic transmission using half-maximal stimulation intensity with a frequency of $0.017 \mathrm{~Hz}$. In some cases a population spike superimposed on the fEPSP was seen when stimulating at half-maximal stimulation intensity. In these cases we reduced the stimulation intensity to spike threshold level for the population spike. When signals were stable during a baseline period of $50 \mathrm{~min}$, repetitive stimulation $(10 \mathrm{~Hz}$, 900 pulses) was applied, after which recording proceeded for another $60 \mathrm{~min}$ at a frequency of $0.017 \mathrm{~Hz}$. Thus, induced synaptic potentiation is reproducible ( $130 \%$ of baseline values), stable, not saturated (Mayford et al. 1996), and sensitive to genemediated actions of corticosterone on LTP (Wiegert et al. 2005).

Slices were treated for $10 \mathrm{~min}$ with corticosterone (SigmaAldrich; 3, 30, or $100 \mathrm{nM})$ or vehicle $(<0.01 \%$ ethanol), either 10 min before and during repetitive stimulation (Fig. 1A1,B1), 40 (to 30) min before (Fig. 1A2,B2), or immediately after (Fig. 1A3,B3) 
A1

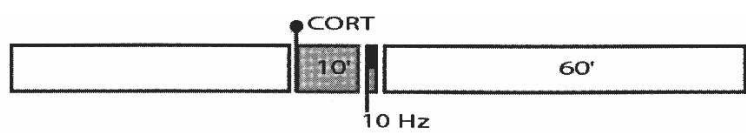

A2

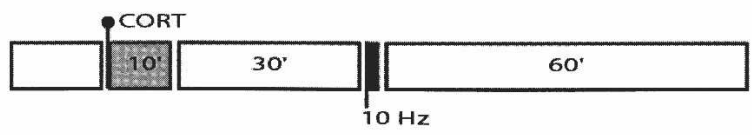

A3

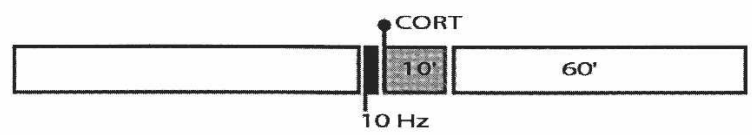

B2

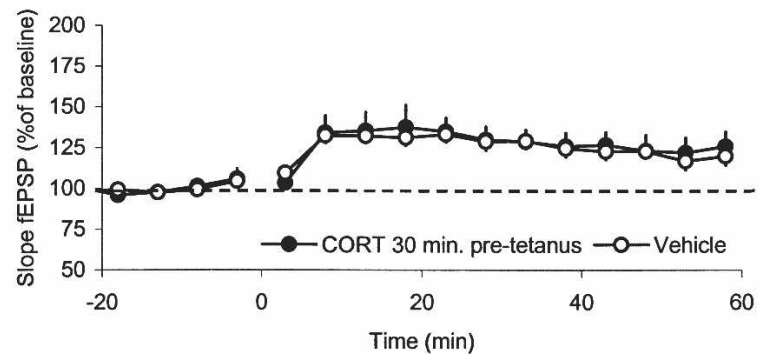

B1

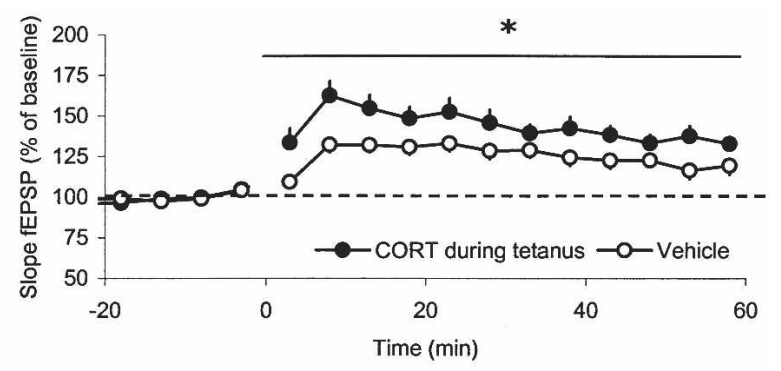

B3

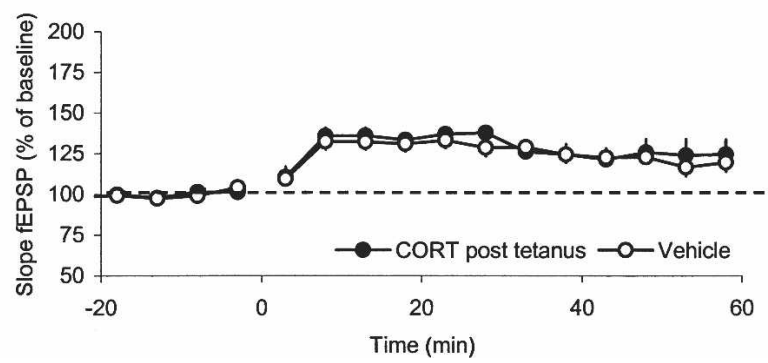

Figure 1. Corticosterone facilitates synaptic potentiation in a specific time window. The schematic representation of the experimental design $(A)$ and the corresponding results $(B)$ are shown. Corticosterone was applied for $10 \mathrm{~min}$ (gray area) at three time points: Starting 10 min before high-frequency stimulation (HFS, 900 pulses at $10 \mathrm{~Hz}$; black area) and lasting until the end of the HFS (A1); starting 40 min before HFS (A2); or starting directly after the end of HFS (A3). In all cases, signals were recorded for 60 min after HFS. (B1) Application of $100 \mathrm{nM}$ of corticosterone to hippocampal slices (filled circles) $10 \mathrm{~min}$ prior to and during repetitive stimulation $(10 \mathrm{~Hz}, 900$ pulses) significantly enhances synaptic potentiation up to 60 min after stimulation, compared with untreated slices (open circles). (B2) When the hormone was administered half an hour before repetitive stimulation ( $t=-40$ to -30 $\mathrm{min}$ ) corticosterone did not affect subsequent synaptic potentiation. (B3) Similarly, when corticosterone administration was started after the repetitive stimulation was completed, no effect was seen on the development and maintenance of potentiation. Statistical analysis was performed over $t=0-60$ min with analysis of variance for repeated measures. ${ }^{*} P<0.05$. For clarity, only average data for a selection of time points (once every 5 min) are shown in these pictures, starting at $t=-18 \mathrm{~min}$. The interval between the last value before and the first value after high-frequency stimulation was left open. Statistical analysis, though, was performed on all data (values for each minute).

repetitive stimulation. In part of the experiments, slices (treated with vehicle or corticosterone) were also incubated with spironolactone (100 $\mathrm{nM}$ and $500 \mathrm{nM})$ or RU 38486 (500 nM) to block mineralocorticoid receptors and glucocorticoid receptors, respectively.

Using ANOVA, statistically significant differences in synaptic potentiation were verified between the experimental groups. $P$-values $<0.05$ were considered significantly different. A student paired $t$-test was used to test the effects of corticosterone on basal transmission.

Corticosterone values at the time of decapitation were low $(11.4 \pm 2.8 \mathrm{ng} / \mathrm{mL}, n=20)$, so that supposedly mostly mineralocorticoid receptors were activated at the start of the experiment. Treatment of slices with $100 \mathrm{nM}$ corticosterone for $10 \mathrm{~min}$ prior to and during repetitive stimulation $(n=10)$ significantly enhanced synaptic potentiation compared with the vehicle-treated slices ( $n=16$; Fig. 1B1). The enhancement was significant when tested over the entire $60-\mathrm{min}$ period $\left(F_{1,24}=6.94, P=0.01\right)$, as well as over the last $20 \mathrm{~min}\left(F_{1,24}=4.74, P=0.04\right)$. A lower concentration of corticosterone $(30 \mathrm{nM})$, such as can be reached during stress (Linthorst et al. 2000; A.C. Linthorst, pers. comm.), also effectively enhanced potentiation over the 60-min recording period ( $n=14 ; F_{1,28}=5.79, P=0.02$; data not shown). Importantly, much lower concentrations of corticosterone $(3 \mathrm{nM})$ did not enhance synaptic potentiation $\left(F_{1,17}=0.03, P=0.87\right)$.

Synaptic potentiation was totally unaffected by $100 \mathrm{nM}$ of corticosterone $(10 \mathrm{~min})$ when the hormone was given either 30 min before (Fig. 1B2; $n=7$ ) or just after (Fig. 1B3; $n=6$ ) repetitive stimulation. Baseline responses were not affected by corticosterone, either for the set of experiments where corticosterone was applied 10 min before and during high-frequency stimulation (average fEPSP slope just before corticosterone: $98 \pm 2.3 \%$ of the value at the start; amplitude during corticosterone: $101 \pm 2.4 \%$, $n=24$ ), or when corticosterone was applied 40-30 min before high-frequency stimulation ( $n=7$; comparison between "before" and "during" corticosterone for fEPSP slope: $P=0.98$ ).

As is evident from Figure 1, effects of corticosterone on synaptic potentiation were seen within $10 \mathrm{~min}$, pointing to a nongenomic pathway. To examine the putative involvement of the classical intracellular receptors, synaptic potentiation was also tested in the presence of specific receptor blockers. In the presence of $100 \mathrm{nM}$ of spironolactone, a concentration that suffices to block mineralocorticoid receptor-mediated effects in hippocampal slices (Karst et al. 2005), corticosterone still markedly enhanced synaptic potentiation $(t=41-60 \mathrm{~min}, n=7$, $F_{1,21}=9.16, P=0.006$; Fig. 2 ). To test whether a higher dosage of spironolactone would reduce corticosteroid facilitation of synaptic plasticity, we also tested $500 \mathrm{nM}$ of spironolactone. Also, in these experiments the effects of corticosterone were not blocked ( $n=5$, data not shown). Synaptic potentiation in the presence of spironolactone alone was not different from the untreated control group $\left(n=5, F_{1,19}=0.06, P=0.81\right)$. Similar observations were made for RU $38486(500 \mathrm{nM})$, which blocks the intracellular glucocorticoid receptors (Moguilewsky and Philibert 1984). Thus, corticosterone significantly facilitated synaptic potentiation in the presence of RU $38486\left(n=7, F_{1,21}=5.49, P=0.03\right.$; Fig. 2), while the antagonist itself had no effect $\left(n=5, F_{1,19}=0.50\right.$, $P=0.49$ ).

Stress is known to facilitate memory formation, but only when the stressor is closely linked to the learning context. These effects are, at least in part, mediated by corticosteroid hormones, which are released in high amounts upon exposure to a stressful situation (de Kloet et al. 1999). Here we tested the hypothesis that elevated corticosteroid levels facilitate hippocampal synaptic potentiation when administered closely to the moment of high-frequency stimulation. Our present experiments demon- 


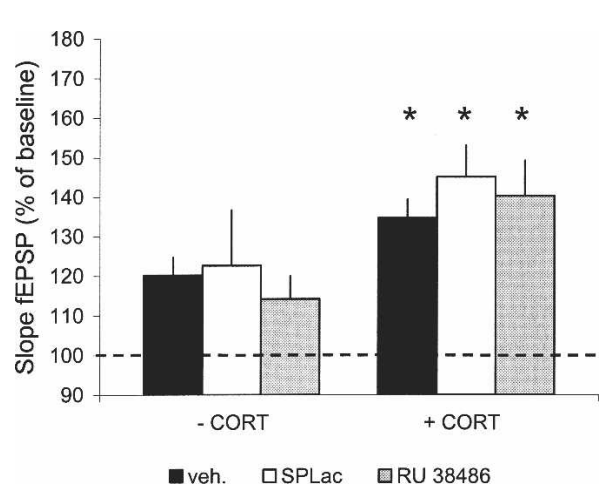

Figure 2. Mineralo- and glucocorticoid receptor antagonists do not block facilitating effects of corticosterone on synaptic potentiation. Corticosterone administered just before and during repetitive stimulation significantly enhanced the averaged synaptic potentiation recorded 40 60 min later when compared with the vehicle-treated slices (black bars). Facilitation persisted when corticosterone was tested in the presence of the mineralocorticoid receptor antagonist spironolactone (SPLac, 100 $\mathrm{nM}$ ), which was present from $t=-25 \mathrm{~min}$ onward. In the presence of spironolactone alone, potentiation was comparable to that seen in vehicle-treated control slices (white bars). Similarly, the glucocorticoid receptor antagonist RU 38486 did not reduce the efficacy of corticosterone to facilitate synaptic potentiation. The potentiation observed when only RU 38486 was perfused (gray bars) was not different from the potentiation in control slices. Data were tested with analysis of variance followed by post hoc multiple comparison of the means. ${ }^{*} P<0.05$ compared with the vehicle-treated group.

strate that high levels of corticosterone, in addition to impairing synaptic potentiation through a slow, gene-mediated mechanism that requires several hours to develop-either using the same stimulation protocol as in the present study (Wiegert et al. 2005) or different stimulation protocols (see for review Kim and Diamond 2002) — can also rapidly facilitate synaptic potentiation. Antagonists of the classical intracellular hormone receptors, which regulate transcription of responsive genes, cannot block this facilitation.

Importantly, corticosterone alone is not able to induce potentiation of the fEPSP. So, it is essential that high levels of the hormone, such as can occur during stress, are present at the time that patterned input reaches the same area (in this case the CA1 hippocampal region); only then does the hormone facilitate synaptic strengthening. The importance of timing found here agrees with earlier studies in Aplysia and rats revealing that the temporal coincidence of either current-induced depolarization or noradrenaline application can result in larger increases in synaptic efficiency than heterosynaptic stimulation alone (Walters and Byrne 1983; Hopkins and Johnston 1988).

Our current results may signify that corticosterone, in concert with other fast-acting stress-induced factors like noradrenalin and corticotrophin-releasing hormone, can promote storage of information when the elevated hormone levels converge in space and time with the patterned input to specific brain circuits that are involved in the consolidation of information. Following non-genomic effects of the steroid hormone (Karst et al. 2005), delayed genomic effects exerted by the same hormone may next prime these circuits such that the threshold for synaptic potentiation is increased, and thus information that reaches the same circuits several hours later is less likely to be encoded. A mechanism for the latter process could involve facilitation of AMPA receptor-mediated synaptic events, as has been described in the hippocampus (Karst and Joels 2005) and in other brain regions (Saal et al. 2003; Dong et al. 2004). This would promote the storage of relevant, salient information while passage of later information, unrelated to the stressful event, is impaired due to occlusion of the AMPA receptors (Stein et al. 2003).

\section{Acknowledgments}

This work was supported by grant \#051.02.010 from the Netherlands Organization for Scientific Research NWO. We thank Mirre Stallen and Pieter Goltstein for their contribution to this study and Maaike van der Mark (Gorlaeus Laboratoria, University of Leiden, The Netherlands) for analyzing the corticosterone samples.

\section{References}

Bliss, T.V. and Collingridge, G.L. 1993. A synaptic model of memory: Long-term potentiation in the hippocampus. Nature 361: 31-39.

de Kloet, E.R., Oitzl, M.S., and Joels, M. 1999. Stress and cognition: Are corticosteroids good or bad guys? Trends Neurosci. 22: 422-426.

de Kloet, E.R., Joels, M., and Holsboer, F. 2005. Stress and the brain: From adaptation to disease. Nat. Rev. Neurosci. 6: 463-475.

de Quervain, D.J., Roozendaal, B., and McGaugh, J.L. 1998. Stress and glucocorticoids impair retrieval of long-term spatial memory. Nature 394: $787-790$

Di, S., Malcher-Lopes, R., Halmos, K.C., and Tasker, J.G. 2003. Nongenomic glucocorticoid inhibition via endocannabinoid release in the hypothalamus: A fast feedback mechanism. J. Neurosci. 23: $4850-4857$

Dong, Y., Saal, D., Thomas, M., Faust, R., Bonci, A., Robinson, T., and Malenka, R.C. 2004. Cocaine-induced potentiation of synaptic strength in dopamine neurons: Behavioral correlates in GluRA $(-/-)$ mice. Proc. Natl. Acad. Sci. 101: 14282-14287.

Hopkins, W.F. and Johnston, D. 1988. Noradrenergic enhancement of long-term potentiation at mossy fiber synapses in the hippocampus. J. Neurophysiol. 59: 667-687.

Karst, H. and Joels, M. 2005. Corticosterone slowly enhances miniature excitatory postsynaptic current amplitude in mice CA1 hippocampal cells. J. Neurophysiol. 94: 3479-3486.

Karst, H., Berger, S., Turiault, M., Tronche, F., Schutz, G., and Joels, M. 2005. Mineralocorticoid receptors are indispensable for nongenomic modulation of hippocampal glutamate transmission by corticosterone. Proc. Natl. Acad. Sci. http://www.pnas.org/cgi/content/full/102/52/19204

Kim, J.J. and Diamond, D.M. 2002. The stressed hippocampus, synaptic plasticity and lost memories. Nat. Rev. Neurosci. 3: 453-462.

Kim, J.J. and Yoon, K.S. 1998. Stress: Metaplastic effects in the hippocampus. Trends Neurosci. 21: 505-509.

Krugers, H.J., Douma, B.R., Andringa, G., Bohus, B., Korf, J., and Luiten, P.G. 1997. Exposure to chronic psychosocial stress and corticosterone in the rat: Effects on spatial discrimination learning and hippocampal protein kinase $\mathrm{C} y$ immunoreactivity. Hippocampus 7: 427-436

Kruk, M.R., Halasz, J., Meelis, W., and Haller, J. 2004. Fast positive feedback between the adrenocortical stress response and a brain mechanism involved in aggressive behavior. Behav. Neurosci. 118: $1062-1070$.

Kuhlmann, S., Piel, M., and Wolf, O.T. 2005. Impaired memory retrieval after psychosocial stress in healthy young men. J. Neurosci. 25: $2977-2982$

Linthorst, A.C., Flachskamm, C., Barden, N., Holsboer, F., and Reul, J.M. 2000. Glucocorticoid receptor impairment alters CNS responses to a psychological stressor: An in vivo microdialysis study in transgenic mice. Eur. J. Neurosci. 12: 283-291.

Losel, R.M., Falkenstein, E., Feuring, M., Schultz, A., Tillmann, H.C., Rossol-Haseroth, K., and Wehling, M. 2003. Nongenomic steroid action: Controversies, questions, and answers. Physiol. Rev. 83: $965-1016$.

Lupien, S.J. and McEwen, B.S. 1997. The acute effects of corticosteroids on cognition: Integration of animal and human model studies. Brain Res. Brain Res. Rev. 24: 1-27.

Mayford, M., Bach, M.E., Huang, Y.Y., Wang, L., Hawkins, R.D., and Kandel, E.R. 1996. Control of memory formation through regulated expression of a CaMKII transgene. Science 274: 1678-1683.

Moguilewsky, M. and Philibert, D. 1984. RU 38486: Potent antiglucocorticoid activity correlated with strong binding to the cytosolic glucocorticoid receptor followed by an impaired activation. I. Steroid Biochem. 20: 271-276.

Oitzl, M.S., Reichardt, H.M., Joels, M., and de Kloet, E.R. 2001. Point mutation in the mouse glucocorticoid receptor preventing DNA binding impairs spatial memory. Proc. Natl. Acad. Sci. 98: $12790-12795$.

Pavlides, C., Ogawa, S., Kimura, A., and McEwen, B.S. 1996. Role of adrenal steroid mineralocorticoid and glucocorticoid receptors in long-term potentiation in the CA1 field of hippocampal slices. Brain Res. 738: 229-235.

\section{Learning \& Memory}


Roozendaal, B. and McGaugh, J.L. 1996. Amygdaloid nuclei lesions differentially affect glucocorticoid-induced memory enhancement in an inhibitory avoidance task. Neurobiol. Learn. Mem. 65: 1-8.

Roozendaal, B., Griffith, Q.K., Buranday, J., De Quervain, D.J., and McGaugh, J.L. 2003. The hippocampus mediates glucocorticoid-induced impairment of spatial memory retrieval: Dependence on the basolateral amygdala. Proc. Natl. Acad. Sci. 100: $1328-1333$.

Saal, D., Dong, Y., Bonci, A., and Malenka, R.C. 2003. Drugs of abuse and stress trigger a common synaptic adaptation in dopamine neurons. Neuron 37: 577-582.

Sandi, C. and Rose, S.P. 1994. Corticosteroid receptor antagonists are amnestic for passive avoidance learning in day-old chicks. Eur. J. Neurosci. 6: 1292-1297.

Stein, V., House, D.R., Bredt, D.S., and Nicoll, R.A. 2003. Postsynaptic density-95 mimics and occludes hippocampal long-term potentiation and enhances long-term depression. J. Neurosci. 23: 5503-5506.

Walters, E.T. and Byrne, J.H. 1983. Associative conditioning of single sensory neurons suggests a cellular mechanism for learning. Science 219: 405-408.

Wiegert, O., Pu, Z., Shor, S., Joels, M., and Krugers, H. 2005. Glucocorticoid receptor activation selectively hampers $N$-methyl-D-aspartate receptor dependent hippocampal synaptic plasticity in vitro. Neuroscience 135: 403-411.

Xu, L., Anwyl, R., and Rowan, M.J. 1997. Behavioural stress facilitates the induction of long-term depression in the hippocampus. Nature 387: 497-500.

Received September 12, 2005; accepted in revised form January 12, 2006. 


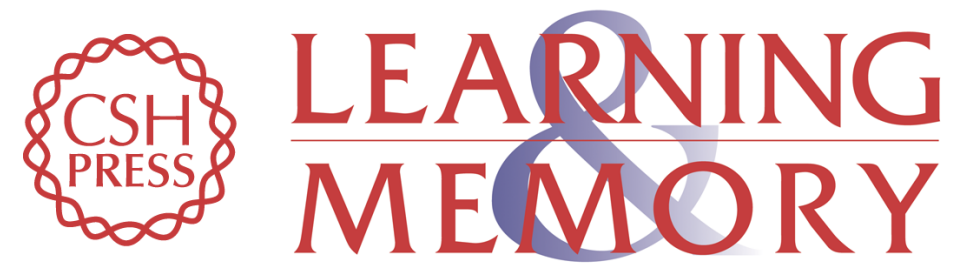

\section{Timing is essential for rapid effects of corticosterone on synaptic potentiation in the mouse hippocampus}

Olof Wiegert, Marian Joëls and Harm Krugers

Learn. Mem. 2006, 13:

Access the most recent version at doi:10.1101/lm.87706

References This article cites 28 articles, 8 of which can be accessed free at: http://learnmem.cshlp.org/content/13/2/110.full.html\#ref-list-1

License

Email Alerting Receive free email alerts when new articles cite this article - sign up in the box at the Service top right corner of the article or click here. 